Article

\title{
SWOT Analysis for Architectural and Structural Solutions Interaction Assessment in High-Rise Buildings Design
}

\author{
Jolanta Tamošaitienè ${ }^{1, *}$, Ernestas Gaudutis ${ }^{2}$ \\ 1 Faculty of Civil Engineering, Vilnius Gediminas Technical University, Saulètekio al. 11, Vilnius, Lithuania; \\ jolanta.tamosaitiene@vgtu.lt \\ 2 Department of City Development, Division of Construction Documents, Subdivision of Design Conditions \\ Vilnius City Municipality, Konstitucijos pr.3, Vilnius, Lithuania; ernestas.gaudutis@vilnius.lt \\ * Correspondence: jolanta.tamosaitiene@vgtu.lt; Tel.: +370 5274231
}

\begin{abstract}
The article reveals distinctive features of the interaction between architectural and structural solutions for the design of tall buildings as well as spotlights the most distinctive cases of expression. In the contemporary world, interaction is turning into the antithesis of the formerly dominant utilitarian attitude and standardization of tall buildings architectural solutions. Meanwhile, the search for rational structural solutions leads to new possibilities of architectural expression. This necessitates the transformation of a structural solution and its adaptation to the need of a modern architect to be exceptional and noticed. Interaction covers the current as well as retrospective and perspective periods. SWOT analysis was used by the authors of the article to assess the interaction between architectural and structural solutions in tall buildings design, select the most important criteria that could be used searching for rational architectural and structural solutions in future by applying multi-criteria decision making methods.
\end{abstract}

Keywords: High-rise buildings, architecture, structural solutions, interaction, SWOT analysis.

\section{Introduction}

Despite of the functional purpose, design of a high-rise building requires a complex assessment of different aspects. This kind of attitude is first related to the scale of an object and peculiarities related to work of complicated structural systems that determine the alteration in spatial composition and facade tectonics. The search for an architectural shape serves as a manifesto that reveals the action encoded in the sub consciousness of an architect, which motivates to choose a more complicated yet less known path in search of new aesthetics. Such buildings not only determine the shift of the contemporary anthropogenic structure providing urban centers with distinctness but also alter the cultural status of the vicinity.

\section{Interaction between architectural and structural solutions used for high-rise buildings}

Different normative documents and sources of literature offer a wide spectrum of criteria that allow describing high-rise buildings. During the research, a high-rise will be any building taller than 35 metres measuring from the base plane. The design of contemporary high-rise buildings still searches for the equilibrium between architectural, structural and engineering solutions (Figure 1), which gave rise to new conceptions of spatial composition and facade tectonics as well as transformation in the composition of a building structure and curtain walls, inescapable entrenchment of engineering systems and dominance of artificial indoor climate [1]. The research focuses on the interaction between architectural and structural solutions in the design of high-rise buildings (Figure 1), which has been fragmentarily investigated [2-5], thus does not allow 
33

34 understanding the multifaceted and intricate effect of this phenomenon on the development of the design of high-rise buildings.

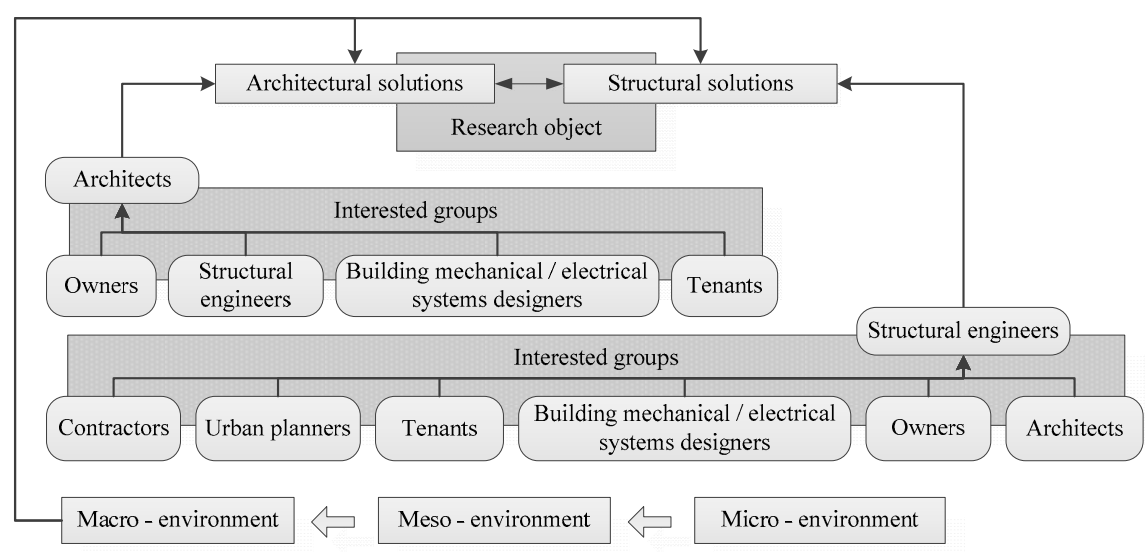

Figure 1. Architectural and structural solutions for tall buildings based on sustainability principles.

Considering the external macro-, meso- and micro- environments, objectives of stakeholders are transferred into design solutions during the design stage. Assessment of the interaction between architectural and structural solutions allows distinguishing a one-sided as well as reciprocal effect. Architectural solutions of a building comprise a spatial composition and facade tectonics (Figure 2).

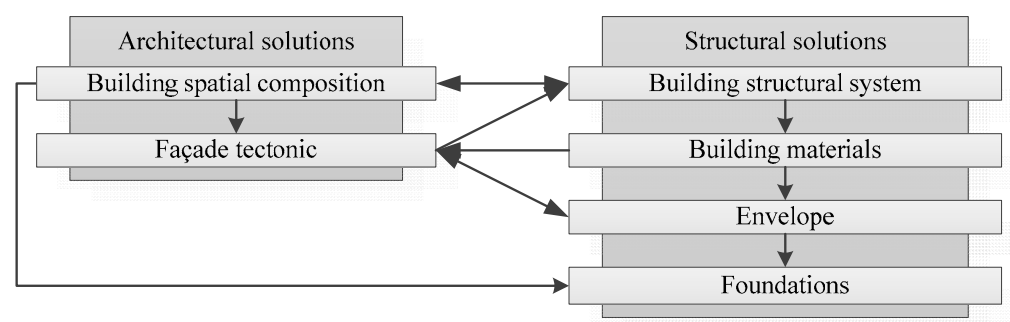

Figure 2. Links between the architectural expression and structural solutions of a tall building.

The relationship between structure and architecture can therefore take many forms (Macdonald 2001). The spatial composition determines the selection of a building structure, numerical values of internal forces in constructional elements as well as interconnections of constructions. A construction may serve as a tangible frame for architectural solutions as well as a tool for development of a spectacular architecture. Facade tectonics selected by an architect for the artistic vision of a building determines solutions of curtain walls. Meanwhile, the knowledge of principles governing the interaction between architectural and structural solutions of load-bearing structures allows satisfying creative ambitions of the architect working on spatial composition and aiming for variety of buildings in the territory. Emergence of new curtain wall solutions allows emphasizing uniqueness of a building in the territorial context as well as leads to development of new architectural styles. Contact between these two extremes of building strategy, has benefit for both the visual and the engineering environments [6].

This section may be divided by subheadings. It should provide a concise and precise description of the experimental results, their interpretation as well as the experimental conclusions that can be drawn.

\section{Methodology}

SWOT method was selected for frequently examples of architectural and structural solutions interaction assessment. SWOT means: Strengths, Weaknesses, Opportunities and Threats. SWOT analysis has been successfully used to resolve problems of various levels in a great number of fields such as business management [7-14], territory planning, structural system design and construction 
sector. Currently, it has been successfully used to analyse links between worldview values of an artist - author of a piece of art displayed in a public urban space - and a customer as well as the public [15]. SWOT method was also used for tall building location in Vilnius city [16], rational structural system selection on initial structural system design stage [17]. The aim of research is to assess the most frequent used ways of interaction between architectural and structural solutions in tall buildings design, define criteria that could be used for architectural or structural solutions selection as part of the most important criteria system by applying multi-criteria decision making methods in further researches.

\section{The effect of architectural solutions on selection of structures for high-rise buildings}

Architecture answers material and spiritual needs of a human being, transmits certain information, immortalises the perception and reclamation of the world as indissoluble internal union during the respective epoch, and gives stimulus for transformation of structural solutions. As a result of effect, structural solutions are assessed on the basis of key requirements for building structures: mechanical resistance, stability, fire safety and safe utilisation.

The effect on selection of structural solutions brought by a spatial composition of an alternate height used for a high-rise building.

Strength - the maximum useful area can be received under comprehensive zoning regulations, ensures improved insulation of lower floors of a high-rise building as well as aeration of the locality and perpendicular way changing rigidity of the structural system. In 1916, once zoning regulations were enforced in New York and led to changes in spatial solutions, buildings had to grow narrower towards the top to improve insolation of lower and upper floors (Figures 3 and 4). This gave rise to new spatial solutions that depended on subjective position of architects and applied stylistic instruments. First and foremost, the comprehensive zoning regulations aimed to ensure improved insulation of lower floors and aeration of streets that turned into canyons. As building stepped upward, the most construction stiffness reached in the lower part of the building, were bending moments are largest.

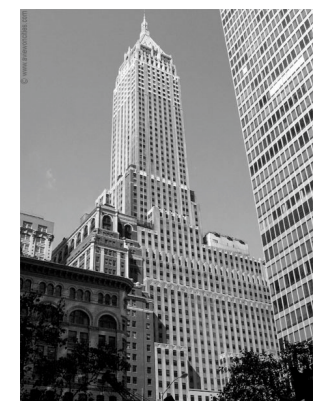

Figure 3. Empire State Building, archit. Shreve, Lamb and Harmon, New York 1931 [37].

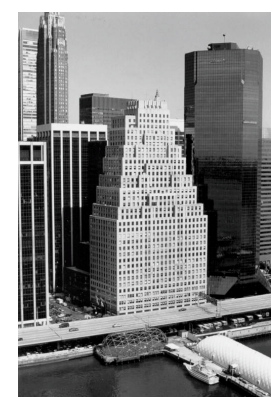

Figure 4. 120 Wall Street archit., Buchman and Kahn, New York 1930 [37].

Weakness - stabilising structures occupy additional space. This means less profitable area on some floors due to transitional structures.

Opportunity - to design expressive spatial compositions of tall buildings. Stepped upward buildings spatial compositions became the source of inspiration for other architects in various American cities, 
96

97

98

99

100

101

102

103

104

105

106 where never have been adopted zoning regulations for tall buildings. One of the postmodernism period examples is Liberty place complex in Philadelphia (Figure 5). The search for new forms of stepped tall buildings emerged in response to the modernist movement. Currently, stepped compositions are used less frequently with the most characteristic examples being the World Trade Centre 3 in New York (Figure 6). Stabilising structures help creating a stepped spatial of buildings (Figure 7).

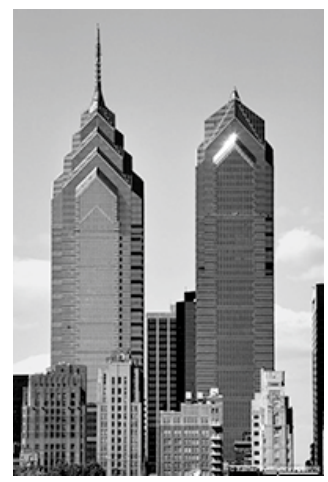

Figure 5. Liberty Place archit. Helmut Jahn, Philadelphia 1990 [25].

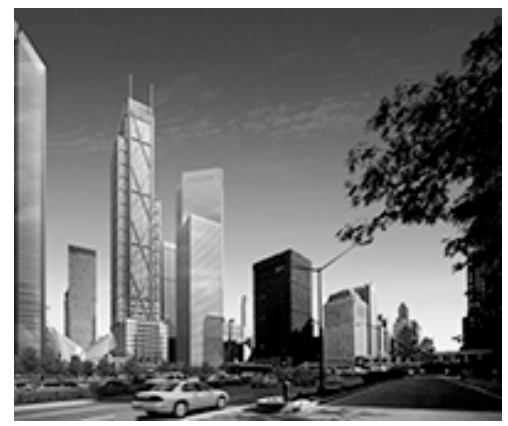

Figure 6. World Trade Centre 3 archit., Roger Stirk Harbour, New York, (under construction) [26].

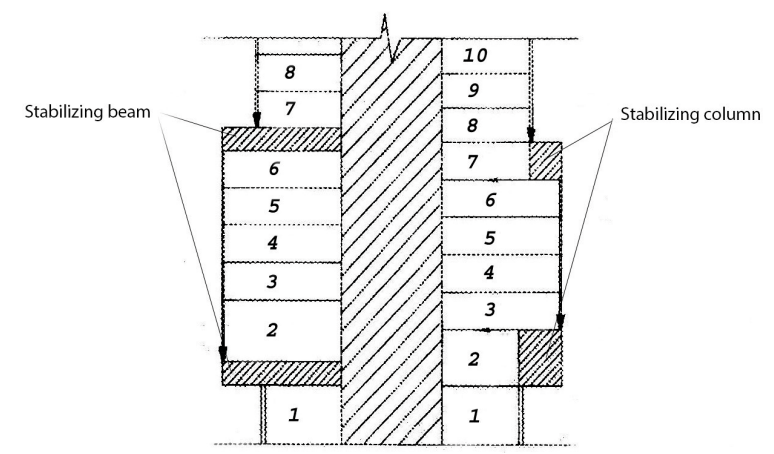

Figure 7. Examples of the arrangement of stabilising structures in the structural system of a building [22].

Threat - the design height of the building increases. Stabilising structures determine a greater design height of the building as well as increased quantity of construction materials required for loadbearing structures and facades.

Based on the SWOT analysis (Figure 8), comprehensive zoning regulations for design of tall buildings resulted in transformation of spatial solutions of new tall buildings. This development emerged from the need to have greater leasing space. Stepped compositions of tall buildings became a usual solution in the design of spatial compositions for tall buildings. Following the results of the SWOT analysis, the design process should consider vertically alternating rigidity of the structural system, space occupied by stabilising beams and columns, which impacts on the increase of the design height of the building. 
Figure 8. The effect on selection of structural solutions brought by a spatial composition of an alternate height used for a tall building SWOT analysis results.

The effect on the building structure brought by accentuation of the main entrance in the facade. Accentuation of the main entrance in the building facade results in alteration of structural solutions for lower floors. They may be implemented using different column spacing, floor height, crosssection of columns and beams, and form of columns.

Strength - allows to avoid monotonous facade and organising movement of people outside the building. Accentuation of the main entrance in the building facade allows for a greater variety of facade solutions and eliminates the uniformity particular to large planes. The main entrance is clearly visible in the composition of the building, so people can choose the shortest way to their destination.

Weakness - greater cost of building materials. Installation of stabilising structures results in greater cost of construction materials. Depending on the selected structure solution, the design height of the first floor changes resulting in greater cost of construction materials required for load-bearing and other structures.

Opportunity - to combine different functional purposes of building rooms in one volume. It is obvious that spacing of columns, which is appropriate for main rooms, will be unsuitable for lobbies. Usually, it is impossible to combine different floor design solutions in one volume just by adjusting spacing of columns; consequently, stabilising structures must be installed, such as beams of reinforced concrete slab (Figure 9).

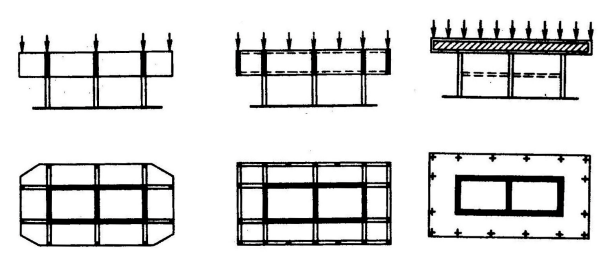

Figure 9. Examples of stabilising structures using beams or reinforced concrete slab [35].

Threat - column cross-sections are irrational from the point of view of structure. To avoid extensive slenderness of vertical design elements, greater cross-sections are planned. However, the accentuation of the main entrance in the building facade using massive reinforced concrete structures is not always rational from the structural point of view. Rather frequently, greater cross-sections of columns are selected on the basis of aesthetic principles.

Based on the SWOT analysis (Figure 10), accentuation of the main entrance in the building facade results in greater cost of construction materials and increasing design height of the first floor. In this case, an opportunity emerges to combine functionally different rooms situated in one volume. The 
148 149

Figure 10. The effect on the building structure brought by accentuation of the main entrance in the facade SWOT analysis results.

The effect on the building structure brought by an organic spatial composition. Wind load is becoming exceptionally relevant in the design of tall buildings due to lightweight curtain walls, larger spans between columns, and lower mass of load-bearing structures and curtain walls. Organic plasticity of spatial solutions may lead to improved exposure of the object content, thus leaving a deeper emotional impact on a spectator. Architectural concept became more sophisticated with new opportunities in modelling of tall buildings based on complicated graphics software. In this scenario the devices which are associated with structural efficiency, which are mostly borrowed from the aerospace industry and from science fiction, are used as a visual vocabulary which is intended to convey the idea of progress and of a future dominated by technology [6].

Strength - allows an expressive spatial composition of the building. A geometric abstraction and sculptural articulation provide a certain visual autonomy in respect of the surrounding context [18]. One of the most characteristic examples are Tour D2 and Phare Tower in Paris (Figures. 11 and 12).

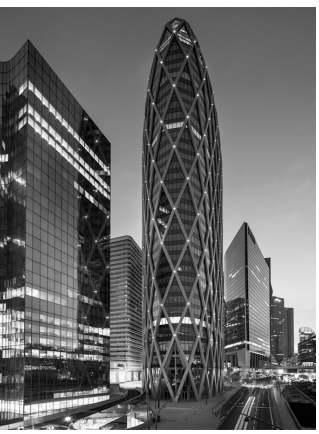

Figure 11. Tour D2, archit. Anthony Bechu, Paris (under construction) [27].

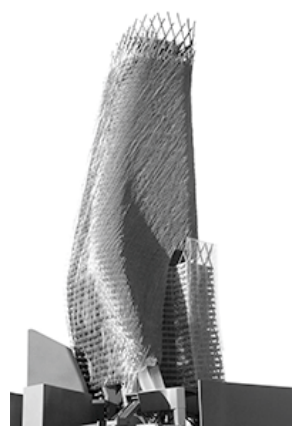


Weakness - aerodynamic tests are required to precisely estimate the effect of the wind on building structures. The mathematical modelling method is less reliable when assessing aerodynamic characteristics of buildings and peculiarities of the surrounding built-over territory [19].

Opportunity - to reduce internal forces and displacements of load-bearing structures. Aerodynamic aspects must be evaluated analysing the distribution of airflows in the territory rather than modelling of a separate tall building. The effect of wind load on the structure may be reduced choosing an aerodynamically effective shape of a building. A shape of a building ensures spatial functioning of structure under lateral loads at the same time creating a reduced wind-resisting surface. Turbulent airflow, which is excited on the side of the building behind the wind, interacts with the surface of the building and causes wind-induced motion. In comparison to rectangular prism, cylindrical shape allows reducing values of wind loads on load-bearing structures from $20-40 \%$. Ellipse-shaped buildings have characteristics equivalent to cylindrical buildings; however, in this case, orientation of the building in terms of predominant winds is important [19]. The effect of wind on building structure may be reduced by selecting an effective shape as well as using additional measures for improvement of aerodynamic characteristics of volumes [19]. Rectangular- or square-shaped inclined corners, rounding of corners and vertical grooves are frequent solutions in the design of tall buildings ensuring protection from excitation of vortexes on the side of the building behind the wind [19]. One of examples of such measures could be Mitsubishi Building in Yokohama, measuring 150 metres in height. In case of the Taipei 101 building, modification of corners allowed reducing the wind-induced bending moment at the fundament by up to $25 \%$ [20]. Openings planned in the volume of a designed building allow reducing the wind pressure on the surface of a building at the top section [19]. Performance of such solutions depends on the height, geometry and location of a building. NEC building in Tokyo and Fuji Xerox building in Singapore remain the most characteristic examples of such solutions. However, in case of the Shanghai World Financial Centre (Figure 13) and the Kingdom Centre in Riyadh (Figure 14), the opening in the volume of a building becomes an architectural instrument, which allows providing a large building with individuality.

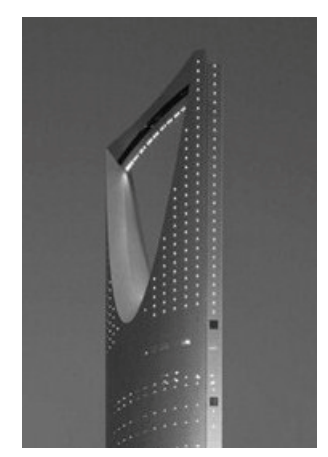

Figure 13. Kingdom Centre, archit. Ellerbe Becket, Riyadh, 2002 [18].

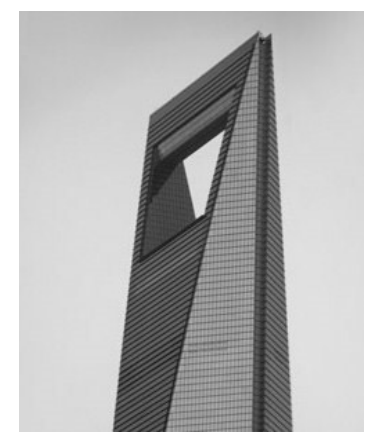

Figure 14. Shanghai World Financial Centre, archit. Kohn Pedersen, Fox, 2008 [18].

Threat - negative impact on closely located buildings and changes caused by near newly erected buildings. Vortexes excited on the side of the building behind the wind may negatively impact on closely situated buildings. Changes caused by newly erected buildings may negate the measures, 
which were used to improve aerodynamic characteristics of a building. Based on the SWOT analysis (Figure 15), new computer software allowed designing complicated spatial compositions of tall buildings.

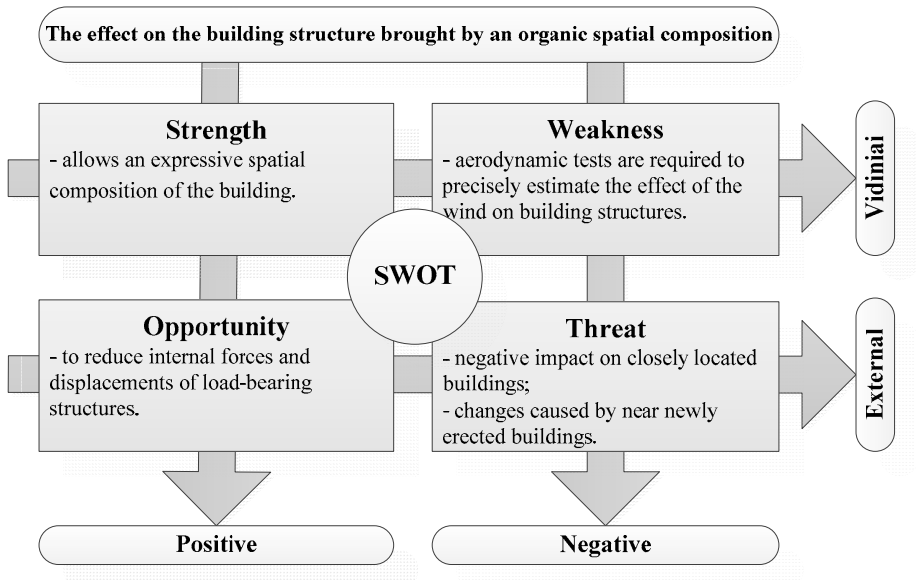

Figure 15. The effect on the building structure brought by an organic spatial composition. SWOT analysis results.

While drafting technical design documents of a single building, clearly defined location and size of the land-parcel makes it difficult to achieve radical changes in the location of the building within the territory that would consider results of aerodynamic tests in the wind tunnel. Thus, shape of a building becomes the measure used to reduce the effect of lateral wind load. However, there is a remaining threat of possible changes brought by near newly erected buildings. Consequently, building of new large-scale objects should not only focus on predominant wind directions but also estimate the effect of the new building on the existing structures.

\section{The effect on tall buildings architectural expression brought by structural solutions selection}

The shapes which are adopted for structural elements are affected, to a large extent, by the nature of the materials from which they are made [6]. The physical properties of materials determine the types of internal force which they can carry and, therefore, the types of element for which they are suitable [6]. In terms of tall buildings, there is an unequivocal effect of structural solutions on the artistic vision, which changes in time depending on the national prosperity. Assessment of architectural solutions encompasses adequacy of the designed building to its functional purpose, contextually of the solution in respect of surrounding buildings, acceptability to the wide public and the cost of architectural solutions.

The effect of building materials on spatial composition of a building. At the time of its development, monolithic reinforced concrete was used for different types of structural systems, which brought the long-wanted plasticity and expression in terms of a shape as well as allowed giving up formerly predominant principles for design of spatial composition, which resulted in a greater variety of buildings within a territory. Structure ignored in the form-making process and not forming part of the aesthetic programme [6]. Different shapes of tall buildings, which emerged in the second half of the 20th century, were symbolic of the desire to give-up the usual rectangular shape of tall buildings. One of the first attempts was the Pirelli Tower in Milan, which inspired other no less original buildings, such as Pan Am Building in New York and the Alpha Tower in Birmingham. It was a sort of tasting of tall buildings that had to be erected in the coming decade.

Strength - variety of spatial solutions for tall buildings, emergence of new architectural styles and variety of spatial compositions of tall buildings. The structural wall system, which can be mounted using monolithic reinforced concrete, gave way to domination of shape over function and turned into a weapon against monotony in urban environment. As if leading actors, new buildings underlined their uniqueness by sophisticated shapes. One of the most characteristic complex of the time is the 
Marina City (Figure 16), which started the change in spatial compositions for tall buildings. The radical shape of the buildings second-guessed the formerly prevailing static and pure shapes particular to modernism. Dynamic structures visually and physically defined the process of movement and transformation into static structure. Unusual aesthetic expression was received by shape manipulations: cutting, turning and twisting. This stimulated focusing on shape expression without giving much thought to insignificant detail. Use of new construction materials in the design of tall buildings liberated spatial compositions of tall buildings from the grip of standardisation and gave rise to postmodernism. The use of monolithic reinforced concrete allowed giving up rectangular forms particular to modernism. Monolithic reinforced concrete was used to erect such buildings in Lithuania as Europa, Arfa and the Vilnius Business Harbour.

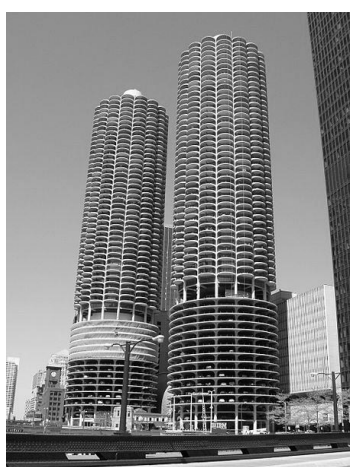

Figure 16. Marina City, complex of buildings Chicago, archit. Bertrand Goldberg, 1964 [1].

Weakness - poor thermal insulation properties and slower construction process. Monolithic construction did not ensure appropriate thermal insulation properties. Use of monolitic concrete in tall buildings construction process had negative effect on building erection time compare to steel frame.

Opportunity - to reduce structural system price. The main building price consist of building materials, products and erection costs. Minimization of cost remains a significant task in building construction process.

Threat - non-functional design of the interior space. However, the aesthetic aspects of the spatial composition upstaged the functionality of functionality envisaged in design solutions. One of the most characteristic examples of such interior design is the Torre Blancas residential building in Madrid [1] (Figure 17). Based on the SWOT analysis (Figure 18), the use of monolithic reinforced concrete for the design of tall buildings opened-up new opportunities for a variety of spatial compositions.

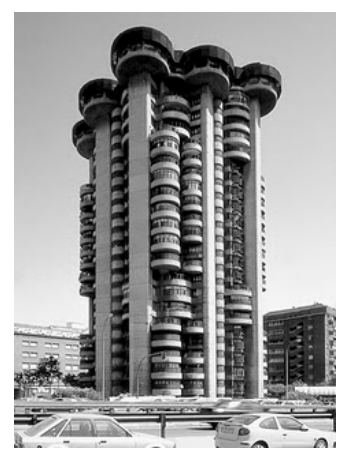


Figure 18. The effect of building materials on spatial composition of a building.

However, the threat of non-functional design solutions remains relevant. Functionality of interior space is one of the most important criteria in assessment of high-quality architecture. Change in spatial solutions of tall buildings resulted in the rise of new architectural styles.

The effect of standardisation and tipification of structural elements of a building plans and facade tectonics. The desire to accelerate construction works resulted in standardisation and tipification of structural elements of tall buildings. Repetition of elements in design of tall buildings may be achieved through standardisation and tipification methods, which were already available back at the end of the 19th century; nevertheless, the scale was evidently different. Reinforced concrete, as a sufficiently cheap material, determined a wide use of structural wall systems in the design of tall buildings.

Strength - provides facade tectonics with individuality, the idea of industrialisation served as a source of inspiration for further creative work of architects. In the 20th century, the architectural expression of residential buildings was influenced by volumetric-precast jetties and elements of loggias with different structural systems. This allowed providing blocks of flats with exceptional tectonic solutions. Such architectural solutions are determined by the idea to strip the functional and structural makeup, respect the specifics pertaining to the purpose of the object and deny the principle of facade absence (Figures19 and 20).

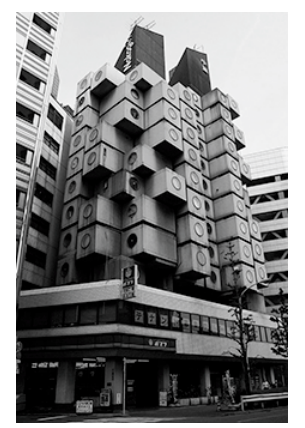

Figure 19. Nagakin Capsule Tower, Tokyo, archit. Kisho Kurokawa, 1972 [30].

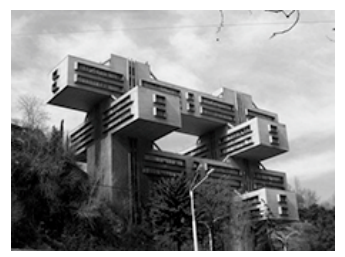

Figure 20. Georgia Bank headquarters, Tbilisi, archit. George Chakhava and Zurab Jalaghania, 1975. [31].

Weakness - monotony of architectural solutions. The problem of industrialisation hides in the attempt to functionally reason the use of typical structural elements. 
Opportunity - to accelerate the process of construction. The value of using a structural wall system made of large-panel elements is determined by such criteria as the speed of construction works, assortment and capacity of construction material producers, and an opportunity to accelerate construction processes.

Threat - large mass of construction elements. This means that the use of spatial blocks in the design of tall buildings is unreasonable due to large mass of structures; large mass of structures creates transportation, warehousing and mounting issues at a construction site.

Based on the SWOT analysis (Figure 21), the use of standardised structural elements defined the architectural expression of tall buildings.

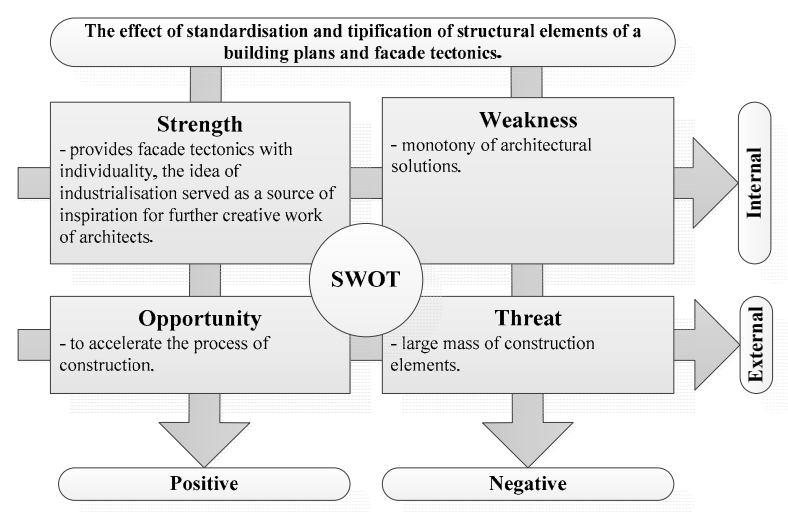

Figure 21. The effect of standardisation and tipification of structural elements of a building plans and facade tectonics.

The strong side of the phenomenon is the inspirational source for further creative work of architects, which resulted in new original architectural solutions.

The effect of the cable-stayed structural system on architectural expression of a building. A cable-stayed structure reflects the spirit and ideas of the epoch as well as search for exceptional architectural solutions. It allowed experimenting with spatial composition of buildings and creating a free interior space without purposeless lower floors, instead of which a public space or a car park could be planned.

Strength - exceptional spatial composition of a tall building and improved use of properties of steel as a building material. The use of the cable-stayed structural system allows achieving visually separated volumes that are interconnected by the stiff core located at the centre. Cable-stayed elements work for extension rather than compression, this way exploiting properties of steel. The load bearing capacity of cables is more than 6 times greater than that of the usual structural steel.

Weakness - limited number of floors. The working scheme of a building does not change with the increase in the load bearing capacity or number of cables, which means that greater load falls on suspensions as well as the stiff core. Consequently, the cable-stayed structural system was used in low-rise administrative buildings.

Opportunity - the cable-stayed structural system allowed implementing the design principle of free interior space and emergence of public spaces in the anthropogenic structure of a city. The synthesis of structural and architectural solutions allowed obtaining a new aesthetic quality of urbanised environment and avoiding the crushing effect of large volumes on the anthropogenic structure of a city. The most characteristic examples are the Standard Bank Centre in Johannesburg (Figure 22), DBS and CPF buildings is Singapore and Marquette Plaza in Minneapolis (Figure 23). Elimination of unnecessary lower floors resulted in appearance of public spaces. 


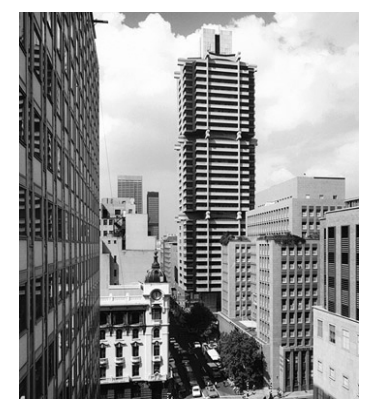

Figure 22. S Bank Centre, archit. HPP, 1968 [2].

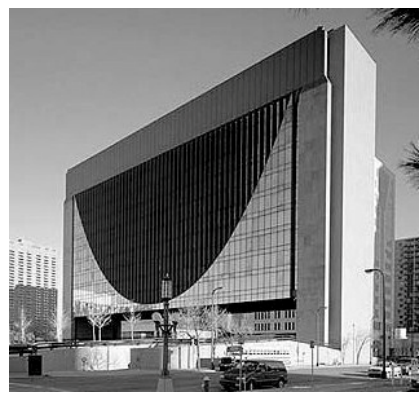

Figure 23. Marquette Plaza. Minneapolis, archit. Ellerbe Becket, 1973 [36]

Threat - negative thermal impact on flexural elements. Sudden changes in temperature result in problems related to installed air conditioning system, which causes more frequent changes in the length of cables and accelerates wear.

Based on the SWOT analysis (Figure 24), the cable-stayed structural system was the instrument used to achieve the variety of spatial compositions of buildings at the time.

The structural system allowed implementing free design of interior space. The use of the cablestayed structural system allows giving up unnecessary lower floors and designing public spaces.

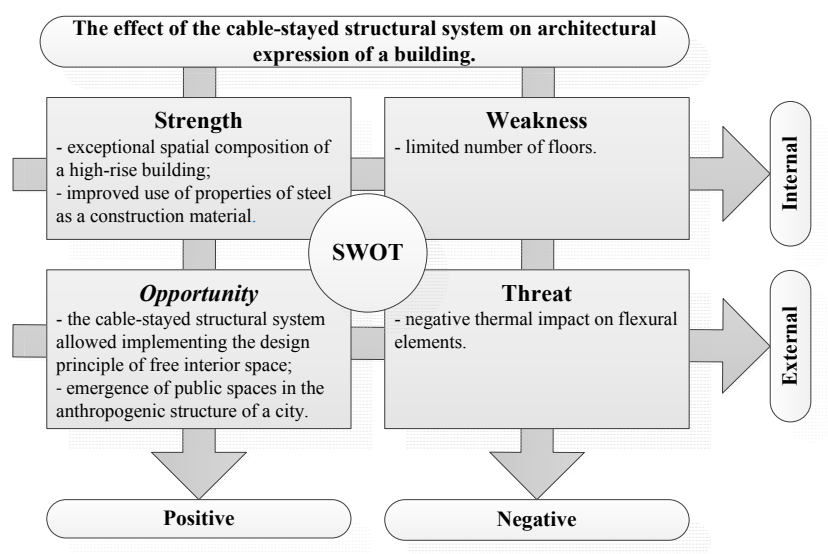

Figure 24. The effect of the cable-stayed structural system on architectural expression of a building.

\section{Reciprocal effect between architectural and structural solutions of tall buildings}

It's the situation in which architect and engineer collaborate fully over the form of a building and evolve the design jointly.

The interaction between geometry and interior space design pertaining to a structural skeleton system. In certain cases, analysis of the interaction between architectural and structural solutions should not be used one-sidedly. Spatial structures expressed the visual link between mechanical properties of materials, geometrical shape of structure and interior design peculiarities. Recently, the use of perimeter diagonals for structural effectiveness and aesthetics has generated renewed interest from architectural and structural designers of tall buildings, producing disagreed structures [4]. 
Strength - exceptional facade tectonics of a tall building is formed and implemented principle of free interior space, emergence of new architectural styles. Composition of the column grid located in the facade is directly dependent on loads that affect the building. First of all, structural solutions expressed individuality of a building, which is opposite to standardised architectural solutions particular to the epoch of modernism [3]. However, as a symbol, the poetised rationalism existed prior to creative work of constructivists, which was defined by the search for aesthetically reasoned rational structural solutions to demonstrate refined engineering precision as an inseparable tool of architectural expression. The structural idea is expressed in architectural solutions of the Menier Chocolate Factory (Figure 25), the building by Jules Saulnier, designed during the industrial revolution. The growing height of buildings and new technical solutions brought novelty into design of tall buildings as well as changed the relationship between architectural and structural solutions. The first instance of the use of shell structure system was registered back in the Sixties when the Dewitt Chestnut Apartments in Chicago were designed. The spatial composition of a building became even more dependent on the geometry of the building structure. Different versions of the shell structure system were used for such buildings as John Hancock, Sears, Standard Oil and World Trade Centre in New York. The exterior grid of columns and beams bears the lateral loads of a building. The exterior column grid with rigid joints is treated as the result of construction process, which has a direct impact on the architectural expression of a building. During the Seventies, new design methods used for tall buildings resulted in search for new more effective structural solutions [1]. In case of the Bank of China in Hong Kong, the structural system is made of two rigidly connected structural elements arranged following the spatial principle (Figures 27 and 28).

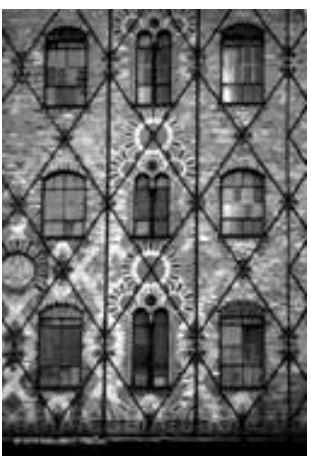

Figure 25. Fragment of the facade of the Menier Chocolate Factory, archit. Jules Saulnier, 1897, Paris [1].

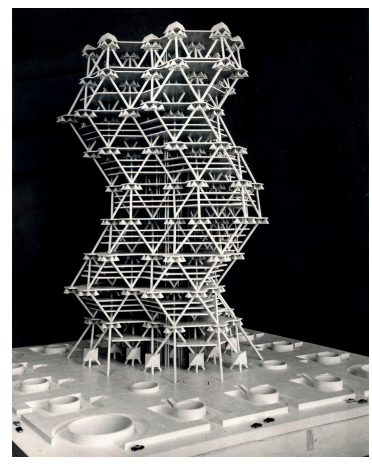

Figure 26. City Tower, archit. Lous Kahn, Anne Tyng, Philadelphia, 1957 (concept) [1]. 


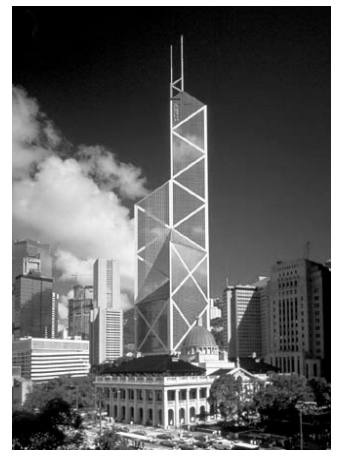

Figure 27. Bank of China, Hong Kong, archit. I. M. Pei, 1990 [18].

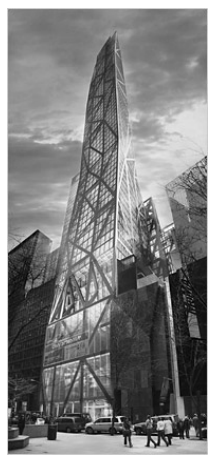

Figure 28. Tower Verre, New York, archit. Jean Nouvel (approved) [32].

As experience shows, flexibility of the interior space planning remains just as important for tall buildings. It is dictated by the change in the concept of work environment. Consequently, administrative buildings are planned with the aim to ensure the greatest possible flexibility between vertical load-bearing columns, which allows for free interior planning.

Architects created new aesthetics as a sophisticated arrangement of structures in facades of a building became a tool for achieving an impressive artistic vision (Figure 26). This gave rise to structural expressionism as a new trend in architecture (Figures 29 and 30). Exhibition of load-bearing structures in facades with emphasised peculiarities of their structure preconditioned such new architectural styles as structural expressionism.

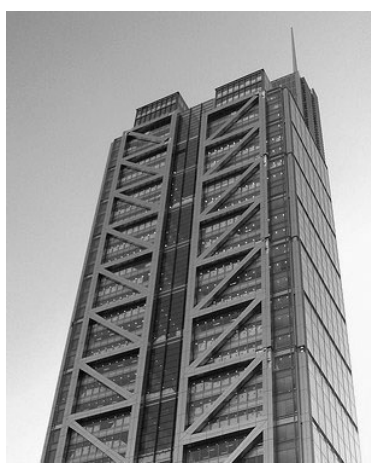




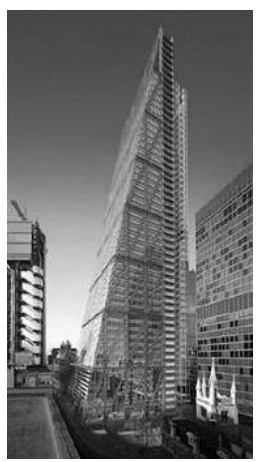

Figure 30. 122 Leadenhall Building, archit. Richard Rogers, London, (under construction) [18].

Weakness - architectural solutions are not universal, large spans have a great structural height. Architectural solutions that appeared as a result of search for different structural systems loose universality with the growing height of a building, which is different to the case of Le Corbusier [1]. This means that architectural solutions may not be simply used in other objects. Increase in structural spans results in increased height of structures. This determines a greater design height of a building and greater cost of construction materials.

Opportunity - the interior of a building is provided with individuality. to increase the rigidity of the structural system. The effect of a structural system of a building is not limited to the exterior as structures may become the elements that provide the interior with distinctiveness (Figures 31 and 32). Reliability and rigidity of a structural system may be increased using horizontal rigidity belts mounted at different heights. They interconnect columns with the stiff core, this way ensuring integrated functioning [21]. In this case, the rigidity of the structural skeleton frame system may be increased by up to $30 \%$. Locations of horizontal rigidity belts in building facades is determined by the height and shape of a building as well as wind loads. Among the most characteristic examples would be the U.S. Bank Centre in Milwaukee, One Federal Street in Boston and the Shanghai World Financial Centre.

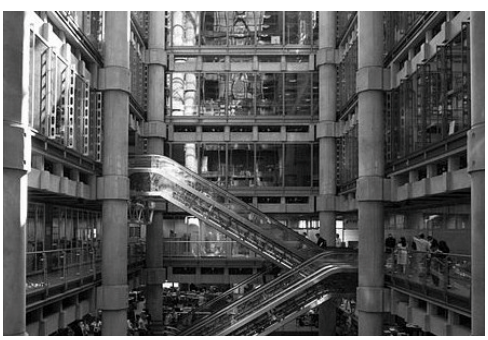

Figure 31. Lloyd bank interior archit. Richard Rogers, London, 1986 [18].

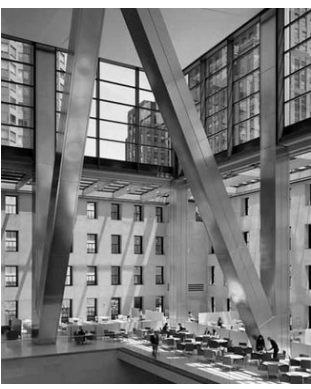

Figure 32. Hearst tower interior archit. Norman Foster, New York, 2006 [34].

Rigidity may be ensured through additional vertical planes inside and division of the stiff core into separate sections. Functioning of the structural system in a tall building is directly dependent on the shape, form and location of the stiff core in terms of symmetry axes in the plan as well as peculiarities of interior space arrangement. Wall size and the number of openings in it (Figures 33 
414

415

416

417

418

419

and 34) directly impact selection of the geometrical shape of diagonal rigidity elements. The shape and position of wall diaphragms in the plan of a building has a great effect on their function under lateral loads. Typical structures that accommodate lateral loads are used. They are implemented using diagonal connections that transfer the lateral displacement of a building onto the column grid.
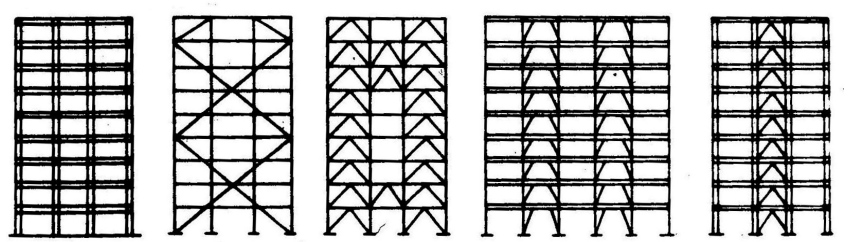

Figure 33. Arrangement of framed elements in a structural system [35].
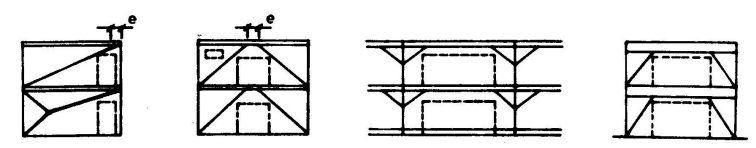

Figure 34. Arrangement of diagonal connections in a structural system of a building [35].

Opportunity - to increase the load bearing capacity of the stiff core and avoid monotony, which is particular to large facade planes. The stiff core is rarely one-sectional. Rigidity may be increased through installation of additional vertical planes, which divide the stiff core into separate sections. Horizontal rigidity belts are a tool that allows visually dividing large facade planes to avoid uniformity. However, the display of a structural solution as an inseparable part of architectural expression remains at the discretion of an architect. In case of the Shanghai World Financial Centre, horizontal rigidity belts remain hidden behind glass facades of the building [22] (Figure 34).

Threat - negative impact on the interior plan of a building, torsion of the building structure. reducing rigidity of the structural system. Structures based on Euclidean geometry emerged back in the Thirties, in works by Richard Buckminster Fuller, Konrad Wachsmann and Robert Le Ricolais [1]. The practical side of Euclidean geometry remained to be one of the largest problems in creative works by Lous Kahn and Anne Grisworld Tyng, which highlighted the conflict between the monumental beauty of a project, resistance of the construction to lateral wind loads and traditional interior space arrangement principles. This caused certain difficulties that emerged while planning interior space and arranging vertical transport systems. Although the project remained in the margins of history of architecture, it gave rise to the search of the reciprocal relationship between the geometry of structural system and volumetric-planned composition of a building. Considering design solutions, arrangement of structural diagonal elements inside a building may be less effective from the point of view of architecture. The design shape of the stiff core and its location inside the building may differ. Under symmetrical location of the stiff core in the building plan, loads become even and no torsional moments emerge. Bending moments may arise with diagonal elements arranged eccentrically in respect of beam span. Rigidity of the structural system reduces in case of large column grid.

Based on the SWOT analysis (Figure 36), free planning of interior space allows creating an office that ensures suitable work conditions for employees during the entire lifecycle of the building [23]. Design solutions pertaining to a building impact on the location, size and configuration of rigidity elements. Architectural solutions determine arrangement of elements on the plan of a building. Experiments with structural systems allowed constructing taller buildings, which had a direct impact on architectural expression of a high-rise building encompassing both the spatial composition of a building and interior solutions of a building. The architect determines significance of building structures while designing the architecture. Design of structures must consider possible negative effect on the plan of interior space to take required measures to avoid it. 

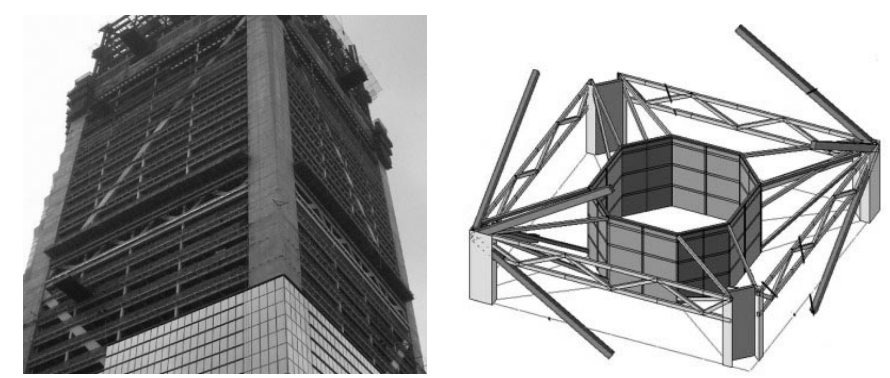

Figure 35. Rigidity belts of the Shanghai World Financial Center [21].

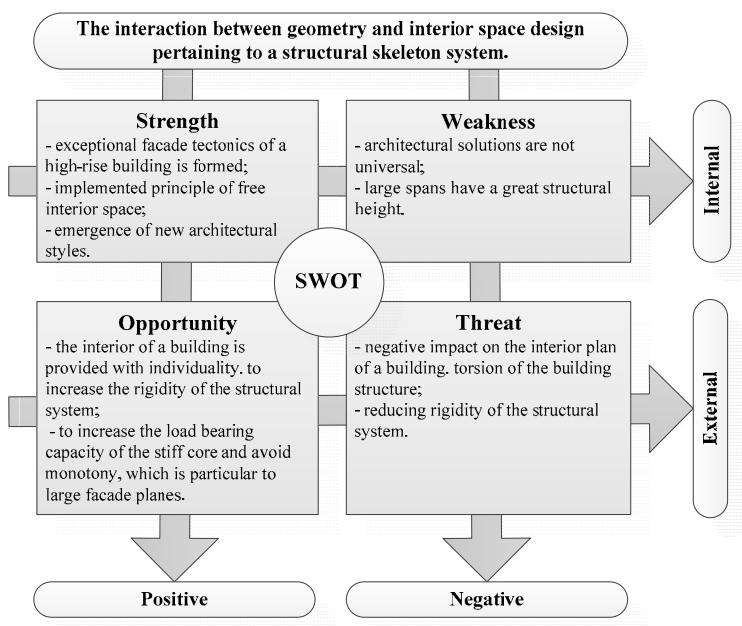

Figure 36. The interaction between geometry and interior space design pertaining to a structural skeleton system SWOT analysis results.

The effect of curtain walls structure on facade tectonics. Facades must ensure the optimal functional requirements and create comfortable conditions inside at the same time protecting the interior from adverse environmental influence such as wind, humidity, cold, heat, noise and etc. Alternative facade solutions provide a building with a new level of quality and alter the conception of contemporary high-rise buildings. A lot of attention is given to energy efficiency and environmental protection.

Strength - assured visual comfort inside the building, emergence of new architectural styles and ensured natural lighting of rooms. Large areas of glass provide visual comfort inside the building. Large external curtain walls made of glass, which were particularly trendy in the Fifties, gave rise to new possibilities of architectural expression and matured the international style philosophy. Large glass walls - screens - offered solutions that were more adequate in terms of the needs of architectural expression. The use of large glass areas in facades of high-rise buildings nurtured the philosophy of the international style. This was conditioned by a number of successfully implemented projects, such as 860-880 Lake Shore Drive and IBM Plaza in Chicago, which allowed assessing the exceptional architectural expression of new buildings with glass as an inseparable part of architectural expression [24]. Once technological issues were resolved, an opportunity arises for entrenchment of the new aesthetics in the design of high-rise buildings. Large areas of glass in facades of buildings allowed ensuring an improved lighting of rooms.

Weakness - large price of facade structures. Glass has never been considered a cheap and universal material, suitable for all possible cases.

Threat - negative impact on microclimate of the interior and negative impact on the architectural expression of facades. However, hermetic solutions of external walls gave rise to new technological problems that were mostly applicable to public buildings. During cold season, the greatest problem is the loss of heat through external walls, which means greater energy costs. The use of external glass walls in practice conditioned intense heat permeability. To protect rooms from direct sunlight, additional measures are used, which ensure an exceptional visual expression for glass surfaces. 
Opportunity - to accelerate construction of external curtain wall structures. It should be underlined that technological aspects had an immense impact on change in facade solutions. New facade solutions not only had to implement the new aesthetics but also accelerate the construction process at a construction site. Facades can be mounted quickly, i.e. works can be finished within an exceptionally short period.

Based on the SWOT analysis (Figure 37), concepts of high-rise buildings gave an impulse to the design of facade structures. The emergence of external curtain wall solutions made from glass conditioned the alteration in facade tectonics and gave rise to new styles of architecture. Larger cost of building materials and accelerated mounting of structures should be considered. This entrenched the new aesthetics for some long decades. The greatest threat still lurks in the negative effect of glass surfaces on the interior microclimate.

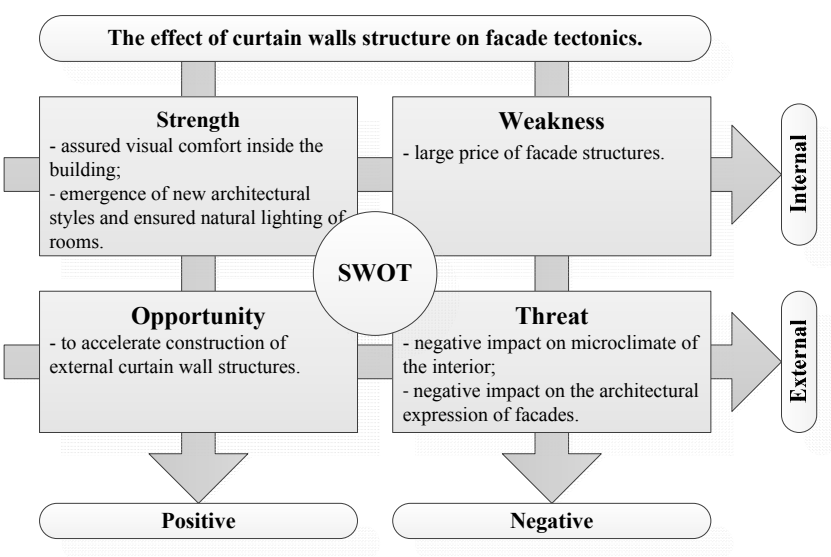

Figure 37. The effect of curtain walls structure on facade tectonics SWOT analysis results.

\section{Conclusions}

The performed analysis demonstrated the inseparable link between architectural and structural solutions in the design of high-rise buildings. Selection of architectural solutions affects the structural system of high-rise buildings as well as emergence of new structural elements and distribution of internal forces. The negative impact of factors on building structures may be reduced during building architectural design process. It demands on investments into the building design process. Experiments with structural systems caused alteration in facade tectonics, spatial solutions, and interior solutions as well as gave rise to new architectural styles. Criteria received subsequent to the analysis of the interaction between architectural and structural solutions in the high-rise buildings design will be used in further researches as a part of important criteria system, for architectural solutions, rational structural system selection from possible alternatives based on sustainable design idea and using multi-criteria decision making methods.

Author Contributions: The individual contribution and responsibilities of the authors were as follows: J.Tamošaitiene - designed the research, performed the development of the paper, regarding the research design, methodology, revised the manuscript. E.Gaudutis - collected and analyzed the data and the obtained results, provided extensive advice throughout the study, findings All the authors have read and approved the final manuscript.

Conflicts of Interest: The authors declare no conflict of interest.

\section{References}

1. Abalos, I.; Herreros, J. Tower and office: from modernist theory to contemporary practice, MIT Press, 2003, p. 305.

2. Eisele, J.; Kloft, E. High-Rise Manual, Birkhäuser Basel, 2003, p. 240.

3. Sarkisian, M.P. Design Tall Buildings: Structure as Architecture, Routledge, 2011, pp. 224.

4. Moon, K.S. Sustainable structural engineering strategies for tall buildings, The Structural Design of Tall and Special Buildings 2008, Volume 17(5), pp. 895-914. 
5. Moon, K.Y. Diagrid Structures for Complex-Shaped Tall Buildings, Advanced Materials Research 2012, Volume 450, pp. 1489-1492.

6. Macdonald, J.A. Structure and architecture, Routledge, 2001, p. 151.

7. Ling, F. Y.Y.; Pham, V.M.C.; Hoang, T.P. Strengths, weaknesses, opportunities, and threats for architectural, engineering, and construction firms: case study of Vietnam, Journal of Construction Engineering and Management 2009, Volume 135(10), pp. 1105-1113.

8. Zhao, Z.Y.; Shen, L.Y.; Zuo, J. Performance and strategy of Chinese contractors in the international market, Journal of Construction Engineering and Management 2009, Volume 135(2), pp. 108-118.

9. Zavadskas, E.K.; Turskis, Z.; Tamošaitienė, J. Selection of construction enterprises management strategy based on the SWOT and multi-criteria analysis, Archives of Civil and Mechanical Engineering 2011, Volume 11(4), pp. 1063-1082.

10. Zavadskas, E.K.; Turskis, Z.; Tamošaitienè, J. Multi-criteria decision making of management effectiveness of construction enterprises based on the SWOT and MCDM, The 6th International Scientific Conference Business and Management 2010: selected papers. May 13-14, 2010. Vilnius: Technika 2010, Volume (2), pp. 11271132.

11. Lee, S.H.; Jeon, R.K.; Kim, J.H.; Kim, J.J. Strategies for developing countries to expand their shares in the global construction market: phase-based SWOT and AAA analyses of Korea, Journal of Construction Engineering and Management 2011, Volume 137(6), pp. 460-471.

12. Kheirkhah, A.S.; Esmailzadeh, A.; Ghazinoory, S. Materials transportation in Iran using the method of fuzzy SWOT analysis, Transport 2009, Volume 24(4), pp. 325-332.

13. Ghazinoory, S.; Zadeh, A.E.; Memariani, A. Fuzzy SWOT analysis, Journal of Intelligent and Fuzzy Systems 2007, Volume 18(1), pp. 99-108.

14. Ghazinoory, S.; Abdi, M.; Azadegan-Mehr, M. SWOT Methodology: A state-of-the-art review for the past, a framework for the future, Journal of Business Economics and Management 2010, Volume 12(1), pp. $24-48$.

15. Lubytė, E. Menas viešose miesto erdvėse: kūrèjo, užsakovo ir publikos vertybių sandraugos klausimas. (Art in public urban spaces: value integrity between authors, customers and the public, in Lithuanian), Town Planning and Architecture 2011, Volume 35(1), pp. 38-50.

16. Tamošaitienè, J.; Šipalis, J.; Banaitis, A.; Gaudutis, E. Complex model for the assessment of the location of high-rise buildings in the city urban structure, International journal of strategic property management 2013, Volume 17(1), pp. 93-109.

17. Tamošaitienè, J.; Gaudutis, E. Complex assessment of structural systems used for high-rise buildings. Journal of civil engineering and management 2013, Volume 19(2), pp. 305-317.

18. Howelwer, E. Skyscraper design of the recent past and the near future, Thames \& Hudson, 2003, p. 240.

19. Irwin, P.; Kilpatrick, J.; Robinson, J.; Frisque, A. Wind and tall buildings: negatives and positives. The Structural Design of Tall and Special Buildings Special Issue: CTBUH 2nd Annual Special Edition: Tall Sustainability. 2008. Volume 17(5), pp. 915-928.

20. Irwin, P. Wind engineering challenges of the new generation of super-tall buildings, Journal of Wind Engineering and Industrial Aerodynamics 2009, Volume 97(7-8), pp. 328-334.

21. Shi, W.; Shan, J.; Lu, X. Modal identification of Shanghai World Financial Centre both from free and ambient vibration response, Engineering Structures 2012, Volume 36, pp. 14-26.

22. Taranath, B. Steel, Concrete, E Composite Design of Tall Buildings, New York: McGraw-Hill, 1998, p. 998.

23. Hascher, R.; Jeska, S.; Klauck, B.M. Office Buildings: A Design Manual, Birkhäuser Basel, 1998, p. 256.

24. Магай, А.А. Архитектура высотных зданий [Architecture of High-Rise Buildings, in Russian]. Москва: Окей - книга. 2007, p. 288.

25. The Skyscraper center. The global tall building database of the CTBUH. One Liberty Place. Available online: http://www.skyscrapercenter.com/building/one-liberty-place/593 (accessed on 3 December 2017).

26. The new archello. 3 World Trade Center by Rogers Stirk Harbour + Partners as Architects Available online: http://www.archello.com/en/project/3-world-trade-center (accessed on 3 December 2017).

27. ArchDaily. Tower D2 / Anthony Bechu Tom Sheehan Architects. Available online: https:/www.archdaily.com/771011/tower-d2-anthony-bechu-tom-sheehan-architects (accessed on 3 December 2017).

28. Pohl, E.B. Phare Tower / Morphosis Achitects Available online: https://www.archdaily.com/20692/pharetower-morphosis-achitects (accessed on 3 December 2017). 
29. Winstanley, T. AD Classics: Torre Blancas / Francisco Javier Sáenz de Oiza Available online: https://www.archdaily.com/157209/ad-classics-torre-blancas-francisco-javier-saenz-de-oiza (accessed on 3 December 2017).

30. Britto, F. Clássicos da Arquitetura: Nakagin Capsule Tower / Kisho Kurokawa. Available online: https://www.archdaily.com.br/br/01-36195/classicos-da-arquitetura-nakagin-capsule-tower-kisho kurokawa (accessed on 3 December 2017).

31. Bank of Georgia Building. Unusual building appears to be haphazardly built from randomly piled bricks. Available online: https://www.atlasobscura.com/places/bank-georgia-building (accessed on 4 December 2017).

32. The Skyscraper center. The global tall building database of the CTBUH. 53 West 53rd. Available online: http://www.skyscrapercenter.com/building/53-west-53rd/317593 (accessed on 5 December 2017).

33. The Skyscraper center. The global tall building database of the CTBUH. 53110 Bishopgate. Available online: http://www.skyscrapercenter.com/building/110-bishopgate/966 (accessed on 5 December 2017).

34. Flashback: Hearst Tower / Foster and Partners Available online: https://www.archdaily.com/204701/ flashback-hearst-tower-foster-and-partners

35. Козак, Ю. Конструкции высотных зданий, [Constructions of High-Rise Buildings, in Russian]. Москва: Стройиздат. 1986. pp. 306.

36. Cities architecture. Marquette Plaza Available online: http://www.citiesarchitecture.com/Building/1969/ Marquette-Plaza.php (accessed on 4 December 2017).

37. Nash, E. P. Manhattan Skyscrapers: Expanded and revised. Princeton Architectural Press. 2005, pp. 240. 